\title{
Formação de professores em contexto de reforma curricular: uma proposta habermasiana em educação matemática
}

\author{
Teacher education in context of curriculum: \\ a habermas's proposal in mathematics education
}

Deise Aparecida Peralta deise.eg@gmail.com

\begin{abstract}
Resumo
Este artigo discute o papel do professor de matemática em contexto de implantação curricular e as possibilidades de validação de uma formação de professores comprometida com o desenvolvimento de um sujeito capaz de emancipar-se na perspectiva da interação entre os mundos vivido, cultural e o sistêmico. Para tanto é tomada como referência a discussão da racionalidade filosófica e pedagógica das orientações para diretrizes do Currículo do estado de São Paulo, a partir do paradigma da Teoria da Ação Comunicativa. Participaram duas professoras que foram envolvidas em entrevistas e filmagens que caracterizaram seus discursos e práticas de ensino e de avaliação, antes e após uma intervenção. A intervenção foi composta por discussões, entre cada uma das professoras e a pesquisadora, sobre características e possibilidades de interpretação de diretrizes oficiais e práticas docentes à luz da teoria habermasiana. Tais discussões se mostraram um recurso de análise da própria prática que impedem a ocorrência de processos de subordinação às questionáveis diretrizes e procedimentos impostos pelas políticas e programas públicos da Secretaria de Estado da Educação de São Paulo.
\end{abstract}

Palavras-chave: Teoria da ação comunicativa; Currículo; Ensino de matemática; Habermas.

\begin{abstract}
This article discusses the work math teacher in the context of curriculum implementation and validation possibilities of a teacher training committed to the development of a subject able to emancipate itself from the perspective of interaction between the worlds lived, cultural and systemic. To do so is taken as the initial reference point the discussion of philosophical and pedagogical rationale of guidelines for guidelines Curriculum of São Paulo, from the paradigm of the Theory of Communicative Action. They attended two teachers who were involved in interviews and footage that characterized his speeches and teaching and evaluation practices before and after an intervention. The intervention consisted of discussions between each of the teachers and the researcher on features and possibilities of interpretation of official guidelines and teaching practices in light of Habermas' theory. Such discussions have proved an analysis feature of the practice that prevents a blind adherence to procedures imposed by the State of São Paulo Education.
\end{abstract}

Keywords: Theory of communicative action; Curriculum; Mathematics teaching; Habermas.

\section{Introdução}

A elaboração de parâmetros e de propostas de unificação de currículos, que expressem orientações aos professores sobre estratégias de ensino e avaliação, tem sido uma constante ao longo das reformas curriculares no estado de São Paulo (AUTOR, 2012). Parece-nos adequado discutir a racionalidade empregada em processos de implantação curricular, bem como, nas ações de formação dos professores nesses processos.

Constitui-se assim, em objeto deste artigo, o confrontar as ações de implantação do Currículo do Estado de São Paulo (São Paulo, 2010) pela Secretaria da Educação do Estado de São Paulo, com a teoria habermasiana. Em acréscimo, advoga-se que é possível conceber diretrizes/parâmetros oficiais que considerem os professores em condições de participar, 
ativamente, da construção de políticas educacionais, particularmente, àquelas relativas à implantação de currículos numa perspectiva que não aquela de razão instrumental.

\subsection{O Currículo do Estado de São Paulo}

A partir dos resultados do SAEB (Sistema de Avaliação da Educação Básica), do ENEM (Exame Nacional do Ensino Médio) e de outras avaliações realizadas em 2007, a Secretaria de Educação do Estado de São Paulo (SEE/SP) elaborou ações com o objetivo de organizar o sistema educacional de São Paulo. A proposição preliminar e provisória de uma base curricular comum para toda rede estadual paulista de ensino foi designada como Proposta Curricular (AUTOR, 2012).

Para que a implantação dessa base curricular comum tivesse sucesso, no começo de 2008, a SEE/SP elaborou o Jornal do Aluno para toda a rede estadual paulista. Durante 42 dias, os alunos fizeram uma recuperação pontual em português e matemática que englobou o material e a Revista do Professor, rebatizada posteriormente de Caderno ${ }^{1}$ do Professor, na tentativa de garantir o acesso dos alunos a uma grade comum de conteúdos. Depois desse período, os cerca de 3,6 milhões de estudantes que participaram do projeto foram avaliados. Os que ainda necessitavam de reforço, continuaram em processo de recuperação no contraturno. Ainda em 2008, começou a ser distribuído o Caderno do Professor no formato de um volume por bimestre, para todas as disciplinas. O material traz sugestões de sequências didáticas e orientações para as ações docentes, apresentando-se como diretriz para o desenvolvimento do conteúdo previsto.

No início de 2009 o Caderno do Aluno, específico por disciplinas e bimestral, foi desenvolvido e entregue aos alunos. Distribuído nesse mesmo ano, para os cerca de 3,3 milhões de estudantes de $5^{\mathrm{a}}$ a $8^{\mathrm{a}}$ séries do Ensino Fundamental e de Ensino Médio, ele traz exercícios, mapas, tabelas, indicadores bibliográficos e dicas de estudo.

Em 2010, a Proposta Curricular passa a ser referida como Currículoº do Estado de São Paulo (SÃO PAULO, 2010). Trata-se de um documento com diretrizes que seguem as dos PCN, mas que incorpora necessidades estimadas, segundo consta ao longo do texto desse documento, como próprias da realidade educacional paulista. Tal documento se apresenta como um conjunto de orientações pedagógicas aos profissionais que integram a rede estadual

\footnotetext{
${ }^{1}$ Caderno no texto escrito com inicial maiúscula se refere ao material didático distribuído, ou que deveria ser distribuído, a alunos e professores da rede estadual paulista.

${ }^{2} \mathrm{O}$ termo Currículo escrito com inicial maiúscula se refere tanto ao documento como as ações de implantação das diretrizes da educação pública no estado de São Paulo.
} 
paulista de ensino público (AUTOR, 2012).

A SEE/SP, segundo informações publicadas na página do Programa São Paulo Faz Escola, afirma oferecer diretrizes para o professor desenvolver nos alunos competências e habilidades que serão alvos de avaliação. Contudo, aparentemente, não há esclarecimentos acerca da incidência dos conceitos de competência e de habilidades na avaliação de desempenho em matemática na educação básica (AUTOR et al, 2013). Tais conceitos se tornam fundamentais ao professor, pois todas as ações diretivas da SEE/SP se dão em torno da orientação aos professores sobre competências relacionadas ao ensino de cada um dos conteúdos disciplinares.

Todas as ações da SEE/SP, acima mencionadas, até o momento, não parecem capazes de reverter os números que apontam desempenhos dos alunos abaixo dos índices esperados. Concentrando ênfase em Matemática, área curricular priorizada neste artigo, o cenário mostra que mais de $50 \%$ dos alunos terminam o ensino médio com rendimento insatisfatório, de acordo com dados do último SARESP, sem apresentar as competências e habilidades adequadas a essa etapa de escolarização. Certamente vários aspectos podem e devem ser considerados nas discussões e interpretações de tais resultados desfavoráveis, entretanto, no âmbito do presente texto a discussão recai sobre o formato das ações usadas pela SEE/SP para orientar os professores. Mais especificamente, a racionalidade dessas ações.

\subsection{A Teoria da Ação Comunicativa}

Dentro da perspectiva da Teoria Crítica e para impor freios à razão instrumental, Jürgen Habermas $(1980 ; 1984 ; 1987 ; 1990)$ desenvolve a Teoria da Ação Comunicativa, que discute a racionalidade da comunicação, sendo orientada para o entendimento e não para a manipulação, contrastando com a racionalidade instrumental. A Ação Comunicativa objetiva a ausência de assimetrias entre os sujeitos que pretendam se entender. Caso o potencial comunicativo não se realize surge a necessidade de Emancipação ${ }^{3}$.

A proposta de Habermas (2001) não é desenvolver um conhecimento finalizado, mas um saber que permita o mútuo Entendimento ${ }^{4}$ e a interpretação da totalidade por cada um dos envolvidos. Através da cooperação e da fala de uns com os outros, o autor acredita na possibilidade de orientar pretensões de validade para além dos contextos particulares,

\footnotetext{
${ }^{3}$ Assim como em Chapani (2010) neste texto é utilizada letra inicial maiúscula quando se tratar de termos que se constituem como conceitos fundamentais da teoria habermasiana.

${ }^{4} \mathrm{Se}$, mediante argumentos, sem nenhuma coação interna ou externa ao discurso, um dos falantes se convence da posição do outro, fazendo, assim, desaparecer o impasse que havia entre eles, então dizemos que eles chegaram a um "Entendimento" e que agora aquela afirmação é objeto de um "Consenso" entre eles (HABERMAS, 2001).
} 
viabilizando probabilidades de fundamentação e de práticas de vida acessíveis a todos. De acordo com o filósofo, o processo de argumentação racional, sendo mediado pela comunicação não distorcida dos indivíduos, permite o estabelecimento de acordos, anunciando condições deliberativas para a produção do saber democratizado.

A Ação Comunicativa pressupõe uma teoria social - a do Mundo da vida ${ }^{5}$ - e contrapõe-se à Ação Estratégica, regida pela lógica da dominação, não envolvendo assentimento ou dissentimento. Habermas (2001) descreve a Ação Estratégica como medida calculista de cunho egocêntrico.

Assim o sendo, a linguagem não é uma mera representação do pensamento, mas um recurso para o Entendimento, envolvendo a compreensão dos Atos de Falas por todos os envolvidos, obtido a partir da argumentação e do prevalecimento do argumento mais adequado. Sendo assim, a Ação Comunicativa se define por "aquelas interações mediadas linguisticamente em que os participantes perseguem com seus atos de fala fins ilucucionários e somente fins ilucucionários" (HABERMAS, 2001, p. 378, itálico no original).

Ao integrar um Discurso, os sujeitos procedem a uma virtualização das suas condições de vida, antecipam, hipoteticamente, que a discussão será realizada em dadas condições que, de fato, não existem, mas devem ser necessariamente postuladas: 1. igualdade comunicativa: os participantes podem falar de igual para igual, sem nenhum tipo de restrição, por maior que seja sua desigualdade social; de modo livre de coerções, por piores que sejam as relações de dominação vigentes; 2. igualdade de fala: os participantes podem empregar todos os tipos de fala, conhecem e podem fazer uso de todo tipo de expressão, explicação, recomendação e juízo para problematizar as pretensões de validez do fragmento do Mundo da Vida em discussão.

Esses pressupostos configuram-se na chamada situação ideal de fala habermasiana, que evidentemente tem um cunho contra fático, constitui em si mesma uma suposição, que não obstante fazemos toda vez que entramos em discussão. Afinal, não fosse assim, a discussão não teria sentido, não haveria motivo para romper o consenso anteriormente pressuposto no quadro da Ação Comunicativa. A discussão consiste, portanto numa situação comunicativa em que suspendemos ou colocamos entre parênteses os motivos ou interesses

${ }^{5} \mathrm{O}$ que o falante diz com seu pronunciamento depende do conhecimento acumulado e realiza-se sob o pano de fundo de um consenso cultural anterior. Consonante a isto, Habermas introduz o conceito de "Mundo da Vida", entendido como o contexto não problematizável, o pano de fundo que propicia os processos de se alcançar o Entendimento. Como ele afirma, no sentido cotidiano o mundo da vida pode ser entendido como aquele em que os atores comunicativos situam e datam seus pronunciamentos em espaços sociais e tempos históricos (HABERMAS, 2003). 
em jogo na Ação Comunicativa cotidiana. (AUTOR, 2012)

Numa interação, um sujeito não pode pretender conseguir Entendimento com outro e exercer influência sobre o mesmo, pois não pode ser intersubjetivamente, considerado um acordo, ações que violam condições sob as quais as forças ilocutórias despertam convicções e originam 'ligações' (HABERMAS, 2002, p. 111, itálicos no original). A Emancipação, portanto, só é possível no contexto de interações mediadas linguisticamente que visam o Entendimento.

Atualmente, diante do contexto brasileiro, parece ser possível afirmar que há um aumento de subordinação das políticas educacionais aos imperativos das políticas econômicas, pois a racionalidade empregada nos processos daquelas são regidas pela racionalidade dos processos dessas (AUTOR, 2012, p.32). Sendo assim, os professores têm reduzida capacidade de participar da construção das políticas educacionais, pois atuam dentro de instituições organizadas, hierarquicamente, no tocante a poder deliberativo, decisório e regulatório. Desta forma é mínima a participação deles na tomada de decisões sobre aspectos como a política educacional em geral, a seleção e a preparação de novos membros, os procedimentos de disciplina interna e as estruturas gerais nas organizações em que trabalham (CARR; KEMMIS, 1988, p. 26).

Em consonância, e corroborando com o já exposto, a seguir este artigo descreve uma pesquisa que traz a teoria de Habermas como possibilidade de formação que tenha o professor como protagonista em contextos de implantação de diretrizes curriculares. Descreve ainda a formação e a atuação dos professores, em termos de conflitos que viveram, diante das imposições de instâncias governamentais.

\section{Questões e objetivos da pesquisa}

Qual a racionalidade subjacente às ações de implantação e implementação do Currículo pela SEE/SP?

É possível conceber diretrizes/parâmetros oficiais que considerem os professores em condições de participarem ativamente da construção de políticas educacionais, particularmente, àquelas relativas às reformas curriculares numa perspectiva do Agir Comunicativo ${ }^{6}$ ?

Sendo assim o objetivo do estudo aqui descrito é analisar uma proposta de formação de professores pautada na TAC em contexto de reforma curricular. E ao analisar: A) Ampliar

\footnotetext{
${ }^{6}$ Referência ao sentido assumido nos pressupostos habermasianos.
} 
a visibilidade sobre formas de elaboração de orientações didáticas para práticas docentes. B) Discutir orientações didáticas expressas no Currículo do Estado de São Paulo nos termos defendidos por Habermas (2001). C) Discutir a forma como professores são envolvidos em processos de reformas curriculares.

\section{Procedimentos Metodológicos ${ }^{7}$}

\subsection{Participantes}

O convite para participação da pesquisa foi efetuado mediante contato pessoal e/ou telefônico com as equipes gestoras das respectivas escolas estaduais. Aceitaram o convite duas professoras que manifestaram interesse por meio da assinatura de termos de consentimento e de esclarecimento. As duas professoras de Matemática, que por ocasião da realização deste estudo, estavam em efetivo exercício na rede pública estadual paulista: uma que lecionava no $9^{\circ}$ ano do Ensino Fundamental ${ }^{8}$ e outra na $3^{\circ}$ série do Ensino Médio. As professoras participantes adotavam, como material de uso diário com os alunos, os Cadernos do Currículo do Estado de São Paulo.

\subsection{Método}

Esta pesquisa é norteada por referenciais metodológicos que visam manter coerência com o agir comunicativo em todo o processo de constituição dos dados.

O pensamento hermenêutico se faz presente no estudo no sentido de que não há um "lugar" privilegiado a partir do qual se pudesse olhar e compreender, definitivamente, as relações que constituem e fundamentam a realidade do professor diante de um contex to de reforma curricular. Esse "lugar" teve que ser construído em processos comunicativos a partir de procedimentos hermenêuticos para as interpretações acontecerem de modo consensual.

\subsubsection{Constituição dos dados}

Etapa 01/Fase 01: Caracterização da formação das professoras e dos discursos acerca da implantação do Currículo do Estado de São Paulo. Ocorreram dois encontros de 2 horas com cada professora.

\footnotetext{
${ }^{7}$ As abordagens e os instrumentos metodológicos utilizados obedeceram aos procedimentos éticos estabelecidos para a pesquisa científica em Ciências Humanas.

${ }^{8} \mathrm{~A}$ organização curricular que as escolas participantes adotavam como usual ainda era série para o ensino Fundamental. Contudo, em respeito a Lei 11.274, de 06 de fevereiro de 2006, dispôs sobre a duração de nove anos para o Ensino Fundamental, na redação desse trabalho usei Ano.
} 
Etapa 01/Fase 02: Caracterização do discurso das professoras sobre as orientações expressas nos Cadernos. Ocorreram três encontros de 2 horas com cada professora individualmente.

Etapa 01/Fase03: Caracterização da prática docente, que segundo as professoras, orientada pelos Cadernos e pelas Matrizes de Referência para Avaliação do SARESP, através do registro em vídeo de cinco aulas consecutivas. Antecedendo ao início das gravações, foi efetuado um período de ambientação da pesquisadora nas respectivas salas de aula de cada professora participante: 1) sem a filmadora; 2) com a filmadora desligada; 3) com a filmadora ligada. Foram filmadas aulas referentes à aplicação de uma Situação de Aprendizagem 01, descrita no Caderno do Aluno e no Caderno do Professor, selecionada pelas próprias professoras, sem que isto representasse qualquer alteração na programação (planejamento) inicial das mesmas.

Etapa 02/Fase 01: Dialogando sobre o conceito de competências. Através de diálogo, de acordo com os princípios habermasianos, em dois encontros, de duas horas cada encontro, as professoras analisaram as aulas registradas, mas não na presença dos vídeos.

Etapa 02/Fase 02: Argumentando diante da exibição dos vídeos da Situação de Aprendizagem 01. Foram exibidos para cada professora, individualmente, os episódios das aulas filmadas sobre a Situação de Aprendizagem 01. A opção por apresentar episódios, e não pelos registros na íntegra, deu-se pela escassez de tempo ${ }^{9}$. A seleção desses episódios priorizou o "recorte" de imagens que corroboram ou contradizem os Discursos das professoras em etapas anteriores, ou ainda, evidenciam aspectos que pudessem fomentar o Diálogo entre pesquisadora e professoras na busca ao Entendimento.

Etapa 03/Fase 01: O principal objetivo dessa etapa foi verificar diante de outra Situação de Aprendizagem (Situação 02) possíveis efeitos das interações ocorridas nas etapas precedentes. As aulas foram registradas em vídeo com procedimento idêntico ao utilizado na filmagem da Situação de Aprendizagem 01.

Etapa 03/Fase 02: Avaliação do Processo- Esse encontro contou com três momentos que se constituíram em três condições distintas para que as professoras pudessem Argumentar sobre a interação com a pesquisadora e os procedimentos da pesquisa. Num primeiro momento

\footnotetext{
${ }^{9}$ As professoras que aceitaram participar da pesquisa tinham como disponibilidade 1 hora semanal para reuniões. Essa uma hora foi cedida pelos coordenadores das escolas e será subtraído do HTPC.
} 
foram exibidos os episódios das aulas filmadas na Fase 01 desta Etapa 03. Na segunda parte da reunião, as professoras estabeleceram comparações entre o que viram nas imagens contendo as aulas sobre a Situação de Aprendizagem 01 e a Situação de Aprendizagem 02. $\mathrm{Na}$ terceira e última parte da reunião as professoras foram indagadas sobre suas impressões em relação as etapas da pesquisa desenvolvida, sobre o processo como participantes de pesquisa e como professores em buscar de condições de formação e/ou de profissionalização docente.

\section{Resultados: descrição e análise}

Em todas as etapas fora garantida a liberdade de Atos de Fala às professoras, ou seja, nesses encontros o Discurso das professoras poderia se tornar protagonista de uma ação de formação. Para tanto, todas essas etapas, compostas por entrevistas (que na verdade eram conversas ou espaços de diálogos), filmagens, reuniões, buscaram respeitar princípios básicos hermenêuticos: a) a garantia e a legitimação de Atos de Falas para pesquisadora e professora; b) liberdade para acordo e desacordo entre professora e pesquisadora, garantindo a condição de Argumentação com Pretensão de Validez; c) objetivos de Entendimento e Consenso.

Atos de Fala numa perspectiva habermasiana destaca o fato de que as pessoas, ao proferirem sentenças, estão também realizando ações e não apenas se reportando a eventos ou a estados de coisas e possui dois níveis de articulação: o da intersubjetividade, com base no qual falante e ouvinte comunicam-se um com o outro e o da objetividade, sobre o qual falante e ouvinte podem chegar a um entendimento relativo aos fatos.

Ao relatarem sobre a formação que receberam as duas professores descrevem apenas características técnicas e práticas, numa clara evidência de terem sido formadas num modelo de racionalidade instrumental que passa a fundamentar, inclusive, suas expectativas em relação a ser professor.

Bom, na faculdade eles se preocuparam em nos ensinar Matemática. Agora a ser professor, só vim a ter ideia do que seria quando vim atuar na rede estadual. (Professora do $9^{\circ} \mathrm{ANO}$ do Ensino Fundamental)

Bem eu estou aprendendo na prática e com os outros colegas. Na faculdade eu era excelente aluna, os conteúdos específicos da área nunca foram um problema. Agora as questões pedagógicas ficaram muito de lado na faculdade, elas foram tocadas de forma muito superficial. (Professora da $3^{\mathrm{a}}$ série do Ensino Médio)

O cenário de reforma curricular parece ter incutido nas participantes a prática e a técnica como ideal de formação e a necessidade de seguir regras impostas pela SEE/SP como algo inerente à prática docente, gerando, inclusive, sentimentos de frustração quando a tentativa de seguir as orientações não parece ser bem sucedida: 
Nossa, a sensação que eu tenho é que não tenho conhecimento suficiente para entender o que eles querem de mim com esse Currículo. Acho que eu precisava fazer psicologia para entender como os alunos aprendem e como ensinar competência. (Professora do $9^{\circ} \mathrm{ANO}$ do Ensino Fundamental)

Sim, eu não quero também ser culpada pelo desempenho insatisfatório dos meus alunos no SARESP. Eu acredito que a equipe que desenvolveu o material tem competência para relacionar o conteúdo com a estratégia correta de ensino visando o desenvolvimento de competências e quem sou eu pra discordar? Eu acho isso mesmo. (Professora da $3^{\mathrm{a}}$ série do Ensino Médio)

Uma tendência subjetiva nas concepções das professoras também é demonstrada ao relatarem suas impressões e expectativas em relação às suas turmas de alunos. Não há menção ao fato das condições para a aprendizagem estarem vinculadas à presença ou ausência de condições para o ensino.

Não posso me culpar por todo um período de escolaridade sem sucesso. O último ano não é o responsável por recuperar todas as competências não desenvolvidas. As atividades dos cadernos não dão conta do que ficou para trás. Não há orientações sobre como recuperar conceitos. Eles tiveram toda uma vida escolar para desenvolver todas essas competências e se isso aconteceu ou não com certeza não podemos culpar o professor do último ano. (Professora da $3^{\text {a }}$ série do Ensino Médio)

É uma turma com sérios problemas de leitura e escrita. Eu sei que não podemos mais falar em pré-requisitos, que temos que falar segundo os textos do Currículo de ensino em espiral. Temos que revisar sempre, mas ninguém me diz como trabalhar com alunos que não sabem ler no $9^{\circ}$ Ano. Os Cadernos desconsideram isso. Essa turma é isso: metade sem alfabetizar. (Professora do $9^{\circ} \mathrm{ANO}$ do Ensino Fundamental)

O levantamento de campo traz ainda uma evidência importante: a prática pedagógica das professoras participantes também não contempla um agir comunicativo, ou seja, a prática docente em sala de aula reproduz a racionalidade presente nas histórias de formações que receberam (graduação e cursos) e nas orientações advindas da SEE/SP. Tal evidência demonstra dificuldades em relação à descolonização do Mundo da Vida, ou seja, para as professoras participantes é difícil a superação dos malefícios provocados pela intervenção da racionalidade instrumental sobre o Mundo da Vida, difícil à interação comunicativa com alunos, outros professores, gestores, autoridades da SEE/SP.

Bom eu fiz como manda nos Cadernos. Tudo igual está lá. Eu pedi que fizessem os problemas que vem em cada atividade. Usamos malha quadriculada, pesquisei outras atividades para testar se eles saberiam resolver em outros contextos. Além, é claro, de tudo eu explicar de novo, ir na lousa fazer para eles verem. (Professora do $9^{\circ} \mathrm{ANO}$ do Ensino Fundamental)

Eu não uso material diferente, mesmo porque eles vão ter que enfrentar o SARESP. (Professora da $3^{\mathrm{a}}$ série do Ensino Médio)

E como preciso dar uma nota ao final do bimestre eu tenho a preocupação que eles tenham o Caderno completo, assim eu tenho no que dar nota. (Professora do $9^{\circ} \mathrm{ANO}$ do Ensino Fundamental) 
Ao ter oportunidade de fazer uso de Atos de Fala, de Argumentar numa perspectiva de Razão Comunicativa, as professoras conseguem analisar, com uma perspectiva Crítica, as condições de trabalho que lhe são impostas:

Eu tenho um passo a passo [contido no Caderno do Professor] que foi feito por especialistas que deveriam estar estudando como as competências se relacionam com cada um dos conteúdos, mas como eu posso ter certeza se estou seguindo certo esse passo a passo para desenvolver competências? Então eu analiso as condições que tive para desenvolver a Situação de Aprendizagem do seguinte modo: eu tive que executar um planejamento feito por outra pessoa correndo o risco de não entender o que a pessoa que idealizou aquelas atividades queria que fosse feito. Eu não planejei, mas tenho a obrigação de fazer exatamente o que a pessoa que planejou queria. (Professora do $9^{\circ} \mathrm{ANO}$ do Ensino Fundamental)

\section{A interação com as professoras orientada para um agir comunicativo possibilitou a} elas analisarem a própria prática no sentido de avaliarem o desempenho dos alunos em função das ações docentes. Diante dessas análises elas conseguiram aproximar suas posturas em sala de aula de ações mais voltadas a uma Razão Comunicativa.

Acho que eu preciso ter mais clareza do que eu quero que os alunos aprendam e a partir disso ter claro o que eu preciso fazer para proporcionar essa aprendizagem. Agora o que eu acho mais dificil: olhar para o aluno e enxergar aprendizagem. Como fazer isso? (Professora da $3^{\mathrm{a}}$ série do Ensino Médio)

Se eu quero que ele avalie uma situação de semelhança eu tenho que oferecer atividades que proporcionem isso. Mas isso pode não ser tão simples quando a gente não sabe exatamente o que objetivar, ou melhor, quando a gente não tem claro o que o aluno tem que fazer e a partir dai o que eu tenho que fazer. (Professora da $3^{\mathrm{a}}$ série do Ensino Médio)

Preciso pensar em que condições o aluno faz. No vídeo nós vemos que eles fazem as Atividades da Situação de Aprendizagem, mas em que condições? Muitos deles fingem que fazem e depois copiam da lousa. O Caderno está completo, porém, fazer a Atividade não comprova aprendizagem e nem o desenvolvimento de competência como era o pretendido. Nesse caso houve um problema com a condição de ensino.(Professora do $9^{\circ} \mathrm{ANO}$ do Ensino Fundamental)

Dessa vez [na Situação se aprendizagem pós-intervenção] eu parei de tentar fazer tudo igual aos Cadernos na tentativa de desenvolver competências por ter obedecido cegamente ao procedimento dos Cadernos. Eu tentei ter em mente qual era o men objetivo, o que eu pretendia que os alunos fizessem e a partir dai idealizei minha aula. Quanto aos alunos eu tinha claro que eles teriam que fazer e falar sobre o conteúdo da aula. E acho que no vídeo dá pra ver a diferença entre aquele outro vídeo das outras aulas, afinal nesse eu os deixo fazerem, os deixo falarem. Eu tinha comigo que eles tinham que se expor. Todos tinham que de alguma forma participar das atividades. (Professora do $9^{\circ} \mathrm{ANO}$ do Ensino Fundamental)

Eu vi que é possivel permitir que eles participem e que é possivel acompanhar o que eles fazem individualmente e depois socializar tudo o que foi feito pensando no coletivo. Dessa vez eu tentei imaginar o que eu quero que eles façam com essas Atividades e mais ainda eu tentei pensar o que eu quero que eles façam a partir dessas Atividades ou ainda o que eles têm que passar a fazer depois de aprenderem sobre a representação de dados estatísticos em gráficos. Dessa vez eu tentei obter deles sinais de que eles sabiam o que estava fazendo, que eles estavam fazendo e 
não copiando. Os Cadernos acabaram ficando completos sem eu precisar passar a resposta na lousa (Professora da $3^{\text {a }}$ série do Ensino Médio)

Diante de conversas em que se tentou manter um Discurso, voltado ao Entendimento e ao Consenso, as professoras tiveram liberdade para Argumentar sobre as relações que envolvem suas práticas de sala de aula. Essa oportunidade de Argumentação fê-las experimentar uma forma de interação voltada à Razão Comunicativa, auxiliando-as a analisar as relações de poder que se sobrepõe à sua atividade docente. Admite-se que esse exercício esse se constituiu conscientes das possibilidades de autonomia sobre a organização dos processos que se estabelecessem em sala de aula e sobre as diretrizes da SEE/SP que lhes são impostas.

\begin{abstract}
Olha, em primeiro lugar eu me sentiria valorizada [se houvesse uma preocupação com o entendimento do professor sobre os conceitos envolvidos no Currículo], pois pra mim é uma humilhação eu não entender esse conceito de competência até hoje. Quando eu estou sozinha com os Cadernos o que eu faço é decorar a sequência em que tudo tem que ser feito. Pensar que eu posso pensar que a avaliação das ações que atestam competências me aproxima da avaliação acerca do aluno ser competente ou não. As orientações contidas nos cadernos não são claras em termos de como avaliar o processo de ensino e pensando bem, na proposição de estratégias de ensino, pois me sinto como tendo que acertar um alvo no escuro. ( Professora da $3^{\mathrm{a}}$ série do Ensino Médio)
\end{abstract}

Sabe o que eu acho (risos) seria mais democrático usar uma linguagem que fosse compreensível por qualquer profissional nas orientações aos professores. Aliás, só poderíamos chamar de orientação se tivessem a função de orientar e orientar só é possivel se a pessoa, a ser orientada, entender o que querem lhe dizer. Se não houver entendimento do que se diz não podemos dizer que é uma orientação. (Professora do $9^{\circ}$ ANO do Ensino Fundamental)

A possibilidade de formar professores dessa forma [com possibilidades de Fala, de Argumentação] seria fantástica. A forma [da interação] de conduzir respeitou o professor como alguém que tem condições de participar do seu processo de formação, alguém que tem condições contribuir com conceitos e processos dentro da escola, alguém que não precisa receber orientações prontas, mas que tem condições de intervir de acordo com a realidade de cada turma. Mesmo que digam que os professores foram envolvidos, nós nunca tivemos a chance de discutir conceitos, de discutir o que facilitaria a nossa vida em sala de aula. Nunca ninguém nos respeitou como sujeitos que poderiam contribuir com todo esse processo. Nesse processo de implantação do Currículo me senti como sendo levada por uma onda e sendo levada cada vez mais, o que diziam pra fazer, eu fazia. .(Professora do $9^{\circ} \mathrm{ANO}$ do Ensino Fundamental)

A tentativa de comunicação livre com possibilidades de Entendimento mútuo entre pares em uma Esfera Pública ${ }^{10}$ democrática, de acordo com relato das professoras, se mostrou um modelo de interação que legitima os professores como profissionais Emancipados.

\footnotetext{
${ }^{10}$ Inspirado por Hanna Arendt, Habermas, sinteticamente, assume como esfera pública o lugar de conflito entre diferentes grupos de interesse, espaço de discussão, fundamentado na capacidade de confrontar argumentos racionais com a opinião baseada na razão.
} 
Eu gostaria de frisar que mais do que o quê você disse o que me marcou foi a forma. Você não impôs uma forma de pensar, você apresentou uma forma de agir e mais ainda me mostrou argumentos que embasavam o que você dizia. E mais ainda não foram argumentos baseados em algum autor, pois você não tentou me convencer que a teoria $X$ diz isso e, portanto, eu deveria fazer isso porque seria o melhor. $O$ argumento foi o que aconteceu com as minhas aulas. Você me convenceu a olhar para as minhas aulas e enxergar nos meus alunos que quando eu faço diferente, eles também fazem diferente. Achei muito legal você me mostrar o que queria olhando para o que eu fazia e não tentando me convencer com ideias. Não digo que as teorias não são boas, mas que levaria muito mais tempo para você me convencer que mudanças são possíveis sem me catequizar, sem me impor algo. Aliás, eu acredito que um pouco da imposição da SEE/SP é justamente por conta da pressa. Eles têm pressa que toda uma rede mude em 04 anos dai eles têm que impor, mas fica a dica que é muito mais rápido a pessoa mudar a partir da consciência das suas próprias ações. (Professora da $3^{\text {a }}$ SÉRIE do Ensino Médio)

Diante dos dados apresentados por esta pesquisa é possível afirmar que uma interação com professores numa perspectiva da Ação Comunicativa demonstra uma íntima relação entre a forma de concepção da atividade docente e a perspectiva de superação das ações invasoras do Sistema ${ }^{11}$ sobre essa atividade. Em outros termos, um Agir Comunicativo apresenta-se como possibilidades de mudanças diante do imperativo da fatuidade. É possível ainda afirmar que a formação docente pautada numa Razão Comunicativa é a única forma de manter a identidade social e individual dos professores, pois respeita o Mundo da vida como esfera que compreende o acervo de padrões de interpretação transmitidos culturalmente e organizados linguisticamente.

Parece admissível ainda, afirmar que a interação para formação de professores proposta nesta investigação respeita a instância intersubjetiva das professoras. Tal instância se contrapõe ao conjunto de atividades orientadas e reguladas estrategicamente pelo objetivo de obter êxito e garantir o sucesso na implantação do Currículo. Nesse contexto, a diferenciação entre Sistema e Mundo da vida ocorre para as professoras, pois lhes são oferecidas condições de análise dos tipos de racionalidade embutidos em cada uma destas instâncias.

A interação relatada neste artigo se configura numa proposta de formação, que persegue o ideal da Ação Comunicativa, por possibilitar aos envolvidos interagirem e, por meio da linguagem, organizarem-se socialmente, buscando o Consenso de uma forma livre de toda a coerção externa e interna. Os Discursos envolvidos nessa interação objetivam fundamentar as pretensões de validez presentes nos discursos das professoras e da pesquisadora.

\footnotetext{
${ }^{11}$ Sistema para Habermas é conceito oposto a Mundo da Vida. No desenvolvimento social, formas sistêmicas de integração diferenciam-se progressivamente do mundo da vida. Sistemas são organizados e delimitados através dos respectivos mecanismos especiais da coordenação das ações, ou seja, o sistema educacional através das secretarias de educação, o sistema político enquanto estado através da educação pública e através da disposição atua, como poder organizado, como meio de sanção para decisões obrigatórias.
} 
Em cada entrevista (ou encontro) o agir comunicativo constitui-se na utopia de um processo de comunicação ideal que remete a uma ordem social ainda não existente, a situação linguística ideal constituindo-se como ideal de um Discurso, que seria perfeito se o modelo de interação proposto permitisse condições ideais de realização. Sendo assim, uma proposta de formação pautada numa Ação Comunicativa foi pressuposta como real e perseguida como possibilidade para que a comunicação pudesse se efetivar. Supondo que a proposta de interação com professores desenvolvida na pesquisa não se constitui na íntegra um fiel exemplar de agir comunicativo, ao menos podemos afirmar que fornece elementos para uma crítica das formas concretas de interação e de discurso, podendo se constituir em um elemento de análise de condições para formação de professores pautada numa Razão Comunicativa.

\section{Conclusão}

Ao analisar o estudo apresentado é possível perceber o potencial da Ação Comunicativa, não só para a função desempenhada pelas professoras (interpretar e implementar diretrizes curriculares), mas para o seu processo, não só de desenvolvimento como também de Emancipação ${ }^{12}$ profissional. O Discurso livre, o uso de Atos de Fala, o exercício da Argumentação e da busca pelo Entendimento visando Consenso possibilitou o desenvolvimento de uma postura crítica frente às ingerências sistêmicas, no sentido de avaliar a validade e a pertinência de certas determinações que procedem da SEE/SP, das diversas instâncias de poder, e incentivar a instauração de modalidades que se vinculem mais intensamente às questões pedagógicas que efetivamente envolvem o dia a dia das professoras participantes, seus respectivos Mundos da Vida.

A racionalidade eminentemente instrumental, pautada numa comunicação meramente estratégica, caracterizou ao longo do tempo, e ainda caracteriza atualmente, as ações da SEE/SP em contexto de implantação de diretrizes curriculares (AUTOR, 2012). Diante de tal constatação, esse estudo a corrobora e sinaliza a necessidade de fortalecimento de ações formativas que promovam espaço para discussões acerca da legitimação das modalidades de

\footnotetext{
${ }^{12} \mathrm{Na}$ obra de Habermas Emancipação pode ser entendida como um processo de conquista e manutenção de autonomia. Para Habermas, o grande obstáculo à emancipação é a "colonização do mundo da vida pelos sistemas" (HABERMAS, 2003). Os dois sistemas sociais são o sistema econômico (que se organiza com base na busca estratégica pelo lucro) e o sistema político (que se organiza com base na busca estratégica pelo poder). Se o mundo da vida não for suficientemente protegido contra as investidas desses dois sistemas, então aspectos que deveriam ser decididos e orientados comunicacionalmente (quer dizer, mediante interações comunicativas no mundo da vida) o serão sistemicamente (quer dizer, a partir da lógica estratégica e dos propósitos dos sistemas). Ao definir mundo da vida como um espaço comunicativo e ao definir emancipação como proteção do mundo da vida contra interferências sistêmicas, já estamos dando por certo que as comunicações do mundo da vida não são livres de coerções internas, simbólicas, sociais, independentes e anteriores às interferências dos sistemas.
} 
participação do professor em processos de implantação curricular. Participação nas decisões e não só na execução de ações impostas.

Na perspectiva da Ação Comunicativa, essas modalidades devem sempre ser avaliadas do ponto de vista do potencial comunicativo que apresentam, ou seja, do processo interativo que promovem por meio da prática do Discurso voltada ao Entendimento. O discurso, e não o agir estratégico, é que deve ser a modalidade que estabelece as condições para a legitimação do pensar e fazer pedagógicos. Assim, as interações com professores com finalidades formativas devem tornar-se um exercício do desenvolvimento de Discurso docente, destinado a buscar o Entendimento acerca dos fatos e dos acontecimentos do mundo.

É possível, então, articular a defesa de uma formação docente que se paute em tornar o professor protagonista autônomo em processos de implantação curricular. Na tentativa de torná-lo um ser autônomo, a formação das capacidades discursivas e argumentativas do professor não o dispensa, tampouco o isenta, de uma sólida formação científica e cultural. Ao contrário, a condição do desenvolvimento da capacidade argumentativa dos professores de matemática vincula-se, entre outras coisas, ao domínio científico, técnico e cultural do conhecimento matemático a ser ensinado. É impossível o professor desenvolver uma convincente argumentação sem o domínio consistente de conteúdos e de métodos. Para Habermas a falta de domínio de uma determinada linguagem - neste caso, o conhecimento matemático - pode impedir um Agir Comunicativo (HABERMAS, 2006).

A proposta descrita neste artigo pode fomentar futuras discussões sobre formas de interação com professores, adequadamente, fundamentadas na TAC. Tais discussões poderiam, ainda, fomentar e corroborar justificativas acerca das potencialidades de uma teoria educacional, fundamentada na Ação Comunicativa, a partir da compreensão da busca de Esclarecimento enquanto processo de Emancipação dos professores. Dentro dessa óptica é possível, ainda, defender que todo o processo de formação de professores deva ter vínculo com crenças, motivos e concepções dos profissionais ou futuros profissionais. Não sendo possível em momento algum desprezar a necessidade de uma avaliação crítica dessas concepções.

\section{Referências}

CARR, Wilfred; KEMMIS, Stephen. Teoría critica de la enseñanza: la investigaciónacción en la formación del professorado. Barcelona: Martinez Roca, 1988.

CHAPANI, Daisi Teresinha. Políticas públicas e histórias de formação de professores de ciências: uma análise a partir da teoria social de Habermas. 2010. Tese (doutorado) Faculdade de Ciências, Universidade Estadual Paulista, Bauru, 2010. 
HABERMAS, Jürgen. Conhecimento e interesse. In: BENJAMIN, W., HORKEIMER, M., ADORNO, T.W, HABERMAS, J. Textos escolhidos. São Paulo: Abril Cultural, 1980. p. 155-164. (Coleção: Os Pensadores).

HABERMAS, Jürgen. Mudança estrutural na esfera pública: investigações quanto a uma categoria de sociedade burguesa. Rio de Janeiro: Tempo Brasileiro, 1984.

HABERMAS, Jürgen. A nova intransparência: a crise do estado de bem estar social e o esgotamento das energias utópicas. Novos Estudos CEBRAP, São Paulo, n. 18, p. 103-114, set. 1987.

HABERMAS, Jürgen. Soberania popular como procedimento. Novos Estudos CEBRAP, São Paulo, n. 26, p. 100-113, mar. 1990.

HABERMAS, Jürgen. Teoría de la acción comunicativa I: racionalidad de la acción y racionalización social. $3^{\text {a }}$ ed. Madri: Taurus, 2001.

HABERMAS, Jürgen. Acções, actos de fala, interacções linguisticamente mediadas e o mundo vivo. In HABERMAS, J. Racionalidade e comunicação. Lisboa: Edições 70, 2002.

HABERMAS, Jürgen.Teoría de la acción comunicativa II: crítica de la razón funcionalista. $4^{\mathrm{a}}$ ed.Madri: Taurus, 2003.

HABERMAS, Jürgen. A ética da discussão e a questão da verdade. São Paulo: Martins Fontes, 2004.

HABERMAS, Jürgen.Técnica e ciência como "ideologia". Lisboa: Edições 70, 2006. SÃO PAULO. Currículo do Estado de São Paulo: Matemática e suas tecnologias. Coordenação Maria Inês Fini: coordenação de área Nilson José Machado. São Paulo: SEE, 2010. 